\title{
High PEEP may have reduced injurious transpulmonary pressure swings in the ROSE trial
}

\author{
João B. Borges ${ }^{1 *}$ D, Caio C. A. Morais ${ }^{2}$ and Eduardo L. V. Costa ${ }^{2}$
}

Vigorous spontaneous inspiratory efforts can lower pleural pressures and increase transpulmonary pressures, worsening existing lung injury. Muscle paralysis [1] may prevent breath stacking and pendelluft associated with high respiratory drive and very negative pleural pressures. A recent and comprehensive study [2] compared two positive end-expiratory pressure (PEEP) strategies and found that an oxygenation-based method to select PEEP resulted in strong inspiratory efforts, high local lung stress, and intensely focused inflammation in dependent lung regions. In contrast, high PEEP rendered spontaneous effort less injurious by lowering the level of spontaneous effort via neuromechanical uncoupling (Fig. 1) and by converting solid-like (more atelectatic) lung to fluid-like (less atelectatic) lung, reducing the vertical gradient of inspiratory local negative swings in pleural pressure. Both mechanisms worked together to promote a more homogeneous lung expansion. One of the limitations of a high PEEP strategy is that mechanical ventilation with PEEP may result in longitudinal atrophy of diaphragm fibers [3]. We postulate that in the ROSE trial $[4,5]$ the use of lung-protective ventilation with high PEEP (instead of a ventilation strategy with low PEEP [6]) reduced potentially injurious transpulmonary pressure swings in both groups, making the muscle paralysis unnecessary and preventing the potential harmful effects of strong spontaneous efforts in moderate-to-severe ARDS.

\section{Acknowledgements}

Not applicable.

\section{Authors' contributions}

JBB prepared the first draft of the manuscript. CCAM and ELC performed the manuscript revision. All authors read and approved the final manuscript.

\footnotetext{
*Correspondence: joao.batista_borges@kcl.ac.uk

'Centre for Human \& Applied Physiological Sciences (CHAPS), King's College London, London, UK

Full list of author information is available at the end of the article
}

Funding

Not applicable.

\begin{abstract}
Availability of data and materials
The datasets used and/or analyzed reported here are available from the corresponding author on reasonable request.
\end{abstract}

Ethics approval and consent to participate

The Animal Ethics Committee approved the experimental investigation from which animal data is reported here.

Consent for publication

Not applicable.

\section{Competing interests}

The authors declare that they have no competing interests.

\section{Author details}

${ }^{1}$ Centre for Human \& Applied Physiological Sciences (CHAPS), King's College London, London, UK. 'Divisao de Pneumologia, Instituto do Coracao,

Hospital das Clinicas HCFMUSP, Faculdade de Medicina, Universidade de Sao Paulo, Sao Paulo, Brazil.

Received: 20 October 2019 Accepted: 28 November 2019 Published online: 11 December 2019

References

1. Slutsky AS. Neuromuscular blocking agents in ARDS. N Engl J Med. 2010; 363(12):1176-80.

2. Morais CCA, Koyama Y, Yoshida T, Plens GM, Gomes S, Lima CAS, Ramos OPS, Pereira SM, Kawaguchi N, Yamamoto H, et al. High positive endexpiratory pressure renders spontaneous effort noninjurious. Am J Respir Crit Care Med. 2018;197(10):1285-96.

3. Lindqvist J, van den Berg M, van der Pijl R, Hooijman PE, Beishuizen A, Elshof J, de Waard M, Girbes A, Spoelstra-de Man A, Shi ZH, et al. Positive end-expiratory pressure ventilation induces longitudinal atrophy in diaphragm fibers. Am J Respir Crit Care Med. 2018;198(4):472-85.

4. The National Heart, Lung, and Blood Institute PETAL Clinical Trials Network, Moss M, Huang DT, Brower RG, Ferguson ND, Ginde AA, Gong $\mathrm{MN}$, et al. Early neuromuscular blockade in the acute respiratory distress syndrome. N Engl J Med. 2019;380(21):1997-2008.

5. Slutsky AS, Villar J. Early paralytic agents for ARDS? Yes, no, and sometimes. N Engl J Med. 2019;380(21):2061-3.

6. Papazian L, Forel JM, Gacouin A, Penot-Ragon C, Perrin G, Loundou A, Jaber S, Arnal JM, Perez D, Seghboyan JM, et al. Neuromuscular blockers in early acute respiratory distress syndrome. N Engl J Med. 2010;363(12):1107-16.

\section{Publisher's Note}

Springer Nature remains neutral with regard to jurisdictional claims in published maps and institutional affiliations. 


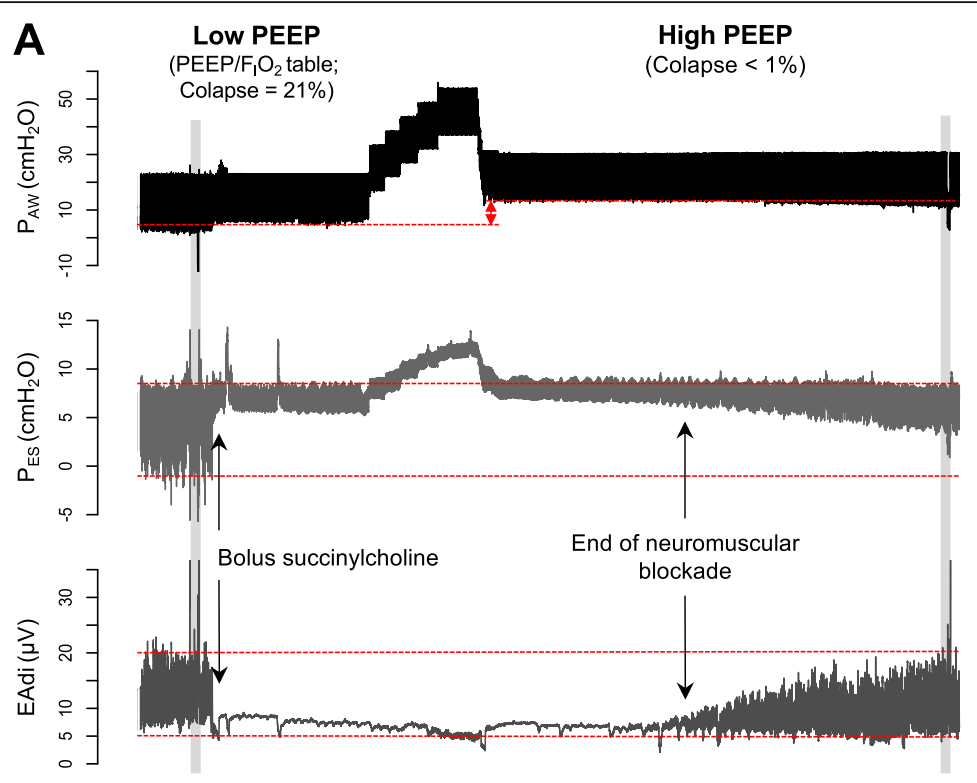

B
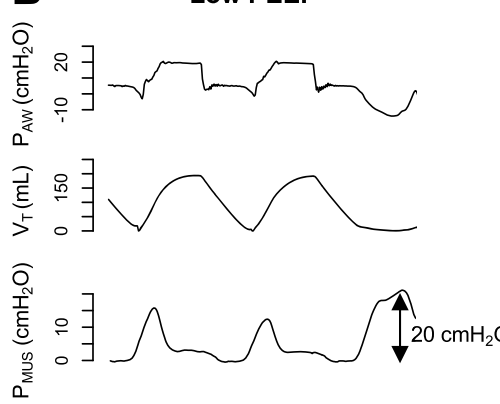

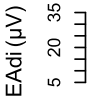

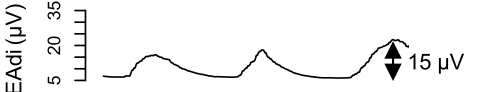

High PEEP
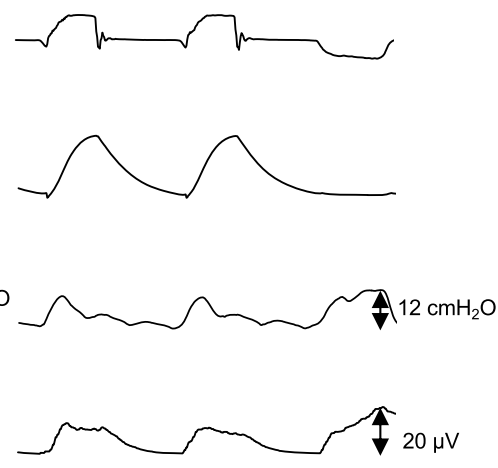

Fig. 1 Intensity of spontaneous effort with low vs. high positive end-expiratory pressure (PEEP) in an experimental model of severe acute respiratory distress syndrome. a Representative waveforms of airway pressure $\left(P_{\mathrm{AW}}\right)$, esophageal pressure $\left(P_{\mathrm{ES}}\right)$, and electrical activity of the diaphragm (EAdi). Note that the magnitude of the negative swings of esophageal pressure was reduced by approximately $50 \%$ when PEEP was increased from $7 \mathrm{cmH}_{2} \mathrm{O}$ (low PEEP/F, $\mathrm{O}_{2}$ table, corresponding to lung collapse $=21 \%$ ) to $15 \mathrm{cmH}_{2} \mathrm{O}$ [PEEP level individually titrated by electrical impedance tomography (EIT), corresponding to lung collapse $<1 \%]$, with similar EAdi. b A zoom into the shaded areas that highlight the induced neuromechanical uncoupling when PEEP was increased, that is, less pressure generated by the respiratory muscles $\left(P_{\text {MUS }}\right)$ for each microvolt of electrical activity $\left(P_{\text {Mus }} /\right.$ EAdi index during low and high PEEP $=1.33 \mathrm{cmH}_{2} \mathrm{O} / \mu \mathrm{V}$ vs. $0.6 \mathrm{cmH}_{2} \mathrm{O} / \mu \mathrm{V}$, respectively) 